\title{
Introductory Routes of Rice to Japan: An Examination of the Southern Route Hypothesis
}

\author{
$\Delta \cdot \Delta \cdot \Delta$ \\ HIROTO TAKAMIYA
}

THE HISTORY OF RICE (Oryza sativa japonica) and rice agriculture in the Japanese archipelago is not a long one. According to the accepted view, rice was introduced into Japan during the period between the Final Jomon and the Early Yayoi, some 2500 to 3000 years ago (D'Andrea 1995; D'Andrea et al. 1995; Sahara 1987; Sasaki 1991). On the other hand, recent phytolith studies indicate that rice may have been in Japan as early as the Early Jomon, approximately 6000 years ago (Takahashi 1997; Yoshizaki 1997, 1998). The earliest evidence of human occupation on this archipelago dates back approximately 30,000 years. Thus the history of rice in the archipelago is only 8 percent of the occupation period based on the accepted view, or 20 percent at most, based on the second view. In other words, rice is unknown to this region for at least 80 percent of Japan's history.

The Early Jomon period rice is thought to be dry-field rice (Fujiwara 1998; Sato 1992; Watabe 1993a; Yoshizaki 1992a, 1997, 1998) and some feel that it did not lead to the large-scale sociocultural changes of the Jomon period (e.g., Hudson n.d.). On the other hand, the Final Jomon to Early Yayoi period rice agriculture was wet-rice agriculture and triggered dramatic changes in every aspect of life in most regions of the archipelago. Indeed, many, if not all, scholars would agree that the effect of the introduction of wet-rice agriculture into Japan was to start the archipelago's agricultural revolution with its first intensive crop production (e.g., Higuchi 1990; Sahara 1978). As in the case of the continents where urbanization emerged after the agricultural revolution, several chiefdoms, and later, states, emerged after the introduction of wet-rice agriculture. Wet-rice agriculture and rice crops are such an important part of the subsistence economy for the Japanese, one well-known scholar once wrote that

since the relationship between the Japanese and rice [wet rice] is so strong, it can be more appropriate to state that the Japanese have become Japanese since the people on the island started to eat rice rather than to state that it has been 2,000 years since the Japanese started to consume rice. (Sahara 1978:128)

In other words, although the history of wet-rice agriculture in Japan is relatively 


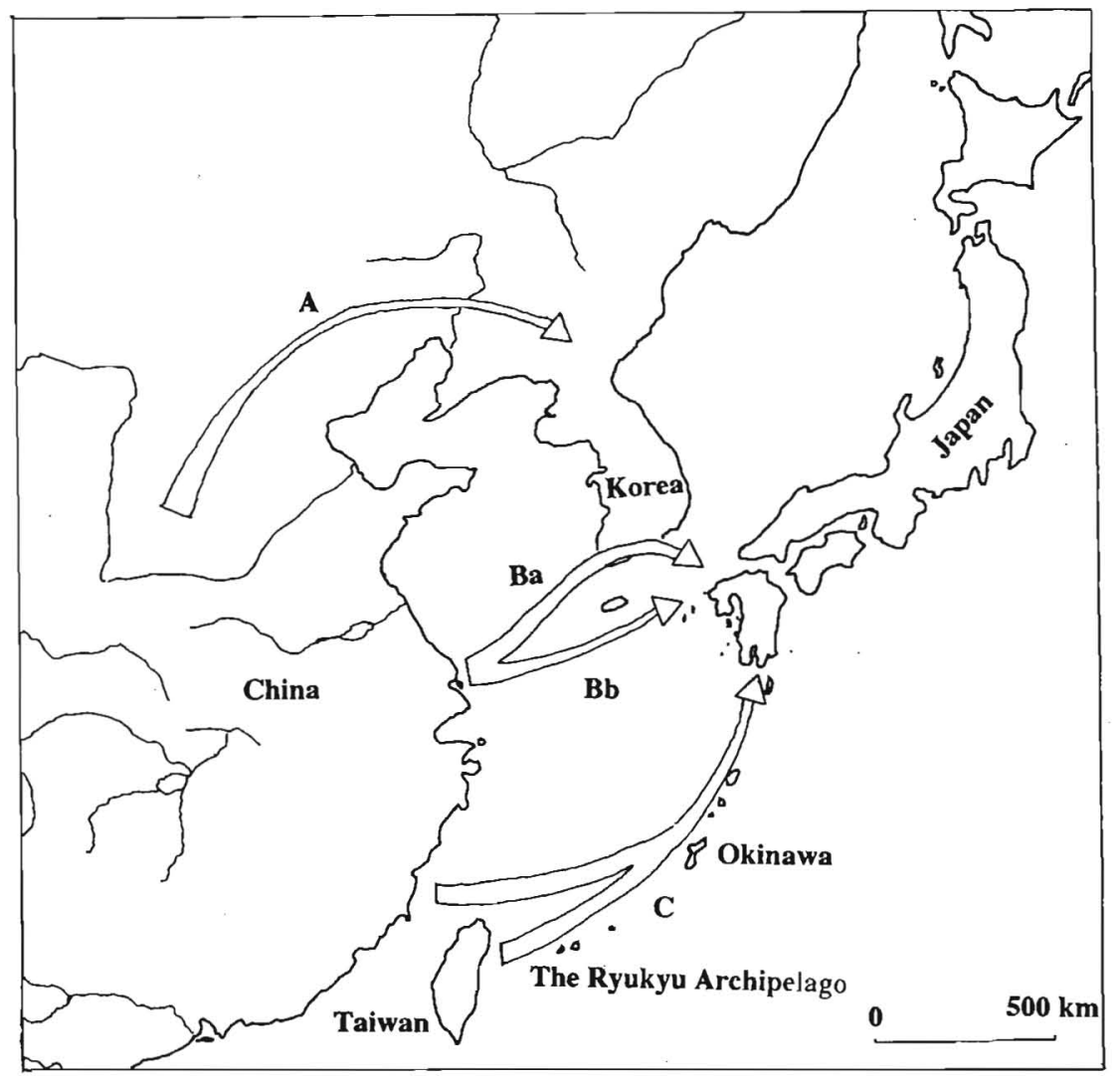

Fig. 1. Three possible routes of introduction of rice to Japan (modified after Akazawa 1982). A: Northern route. Ba: Chanjian route (via southern Korea). Bb: Chanjian route (direct route). C: Southern route.

short, its impact on Japanese history, culture, and society has been tremendous (e.g., Higuchi 1990). Among the many research themes related to rice, the two most pervasive themes are probably the origins of rice agriculture in Japan and the introduction routes of wet-rice agriculture to Japan.

Rice may have been known to the people of the archipelago as early as the Early Jomon and certainly by the Late Jomon period, as mentioned above. Three major introduction routes have been proposed: the Northern, the Chanjian (central coastal China), and the Southern routes (e.g., Sahara 1987; Sasaki 1971, 1991; Sato 1992; Watabe 1993a) (Fig. 1). At the moment, the Chanjian (central coastal China) route seems to be the most widely accepted, although the other two have not been completely discarded and are frequently mentioned in many textbooks on Japanese prehistory. This paper focuses on an evaluation of the Southern route. ${ }^{1}$

Originally known as the Ocean Road hypothesis, the Southern route was proposed by the well-known ethnographer, Kunio Yanagita, in 1952 (Yanagita 1993). In Yanagita's Ocean Road hypothesis (1993 [1952]), farmer-fishers from southern China were shipwrecked and drifted ashore to Miyako Island of Oki- 


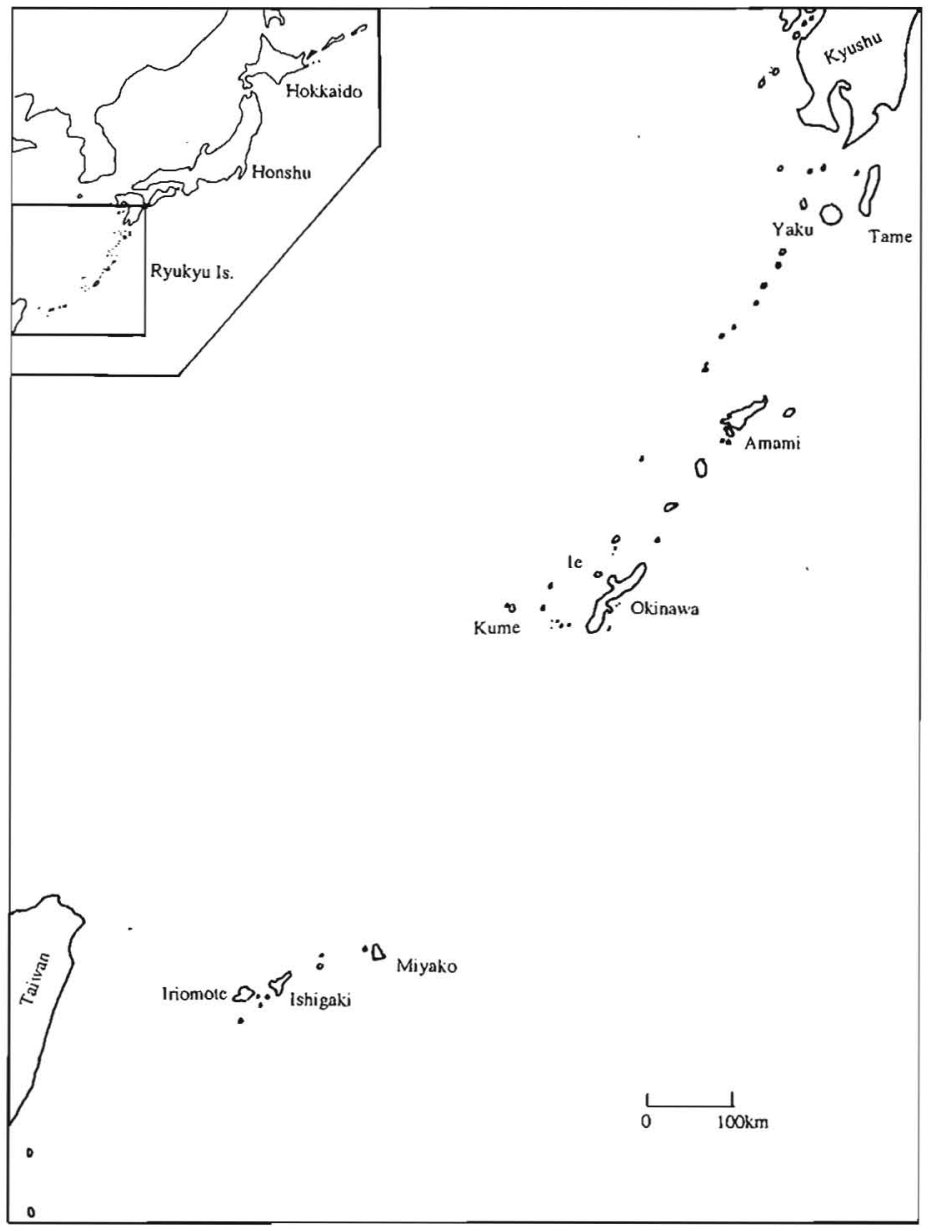

Fig. 2. The Ryukyu archipelago.

nawa (Fig. 2). There they found cowrie (Monetaria sp.) shells, which were used as coins and thus the most valued item in Mainland China. Attracted to cowrie shells, the drifters went back to the mainland to get their families and returned to Okinawa with wet-rice agriculture. Then they traveled northward to look for an adequate location for wet-rice agriculture and finally landed in Kyushu, from where wet-rice agriculture spread to the rest of Japan (Yanagita 1993 [1952]).

Since Yanagita proposed this hypothesis, many scholars (several of them will be introduced shortly after this section) have considered the possibility of the Ocean Road hypothesis. These scholars mainly consist of archaeologists, ethnographers, and botanists. One consequence of this research is the possibility that dry-field rice ( $O$. sativa javanica) was introduced into Japan by this Southern route in the Jomon period (Fujiwara 1998; Sato 1992; Watabe 1993a). This new possibility is referred to as the "New Ocean Road" hypothesis here in order to distinguish it from Yanagita's hypothesis (see Watabe 1993c). First I review information obtained by these scholars over the last twenty years. Then I examine the Ocean 
Road hypothesis based on palaeoethnobotanical data collected from the Takachikuchibaru shell midden (second to fourth centuries A.D.) and the Nazakibaru site (eighth to tenth centuries A.D.). The archaeobotanical data are the best way to understand the relationship between people and plants and thus to test Yanagita's hypothesis.

\section{THE SOUTHERN ROUTE HYPOTHESIS: ON THE BASIS OF CIRCUMSTANTIAL DATA}

Archaeological research conducted on the Ryukyu archipelago since the 1950 s has been intensive, particularly since the chain of islands reverted to Japan in 1972. Numerous new findings have been made. For example, the discovery of Pleistocene human skeleton remains, including the well-known Minatogawa fossil, in the late 1960s demonstrated that this region was occupied by people as early as 18,000 to 32,000 years ago (Baba 1993; Doi 1997). I have hypothesized that these people either left this region or died out by the end of the Pleistocene (Takamiya 1996a, 1997). The recovery of fingernail-impressed pottery from the Toguchiagaribaru site in the 1970 s pushed back the date of Holocene human occupation of the islands much earlier than previously believed (Yomitan Village Board of Education 1977). Moreover, during the 1970s the archaeological excavation conducted at the Murokawa shell midden (Okinawa City Board of Education 1979), together with the data from the Toguchiagaribaru site, has provided a framework for the chronology of Okinawan prehistory (Table 1).

In the 1980s, the data obtained from the Sinugudo (Okinawa Prefecture Board of Education 1985) and Kogachibaru (Okinawa Prefecture Board of Education

Table i. Chronology of Prehistoric Okinawa (the Central Ryukyu)

\begin{tabular}{clcc}
\hline SCHEME 1 & SCHEME 2 & ${ }^{14}$ C DATING (B.P.) & MAINLAND JAPAN \\
\hline Palaeolithic & Palaeolithic & $32,000 \pm 1000^{\mathrm{a}}$ to & Palaeolithic \\
Shell midden & Jomon & $18,250 \pm 650^{\mathrm{b}}$ & $\begin{array}{c}\text { Jomon } \\
\text { Incipient } \\
\text { Initial }\end{array}$ \\
Initial & Initial & $6670 \pm 140^{2}$ & Early \\
& Early & $6450 \pm 140^{2}$ & Middle \\
Early & Middle & $4880 \pm 130^{2}$ & Late \\
Middle & Fate & $3370 \pm 80^{2}$ & Final \\
Late & Final & $3600 \pm 80^{2}$ & Yayoi to Historic \\
& Yayoi-Heian & & \\
Gusuku & Early & & Historic \\
\hline
\end{tabular}

Note: Two chronological schemes have been proposed for the prehistory of Okinawa: Scheme 1 and Scheme 2. I use Scheme 2 because most readers of this paper are likely to be familiar with this scheme.

a After Hiroe Takamiya 1994a

b After Hiroe Takamiya 19946 
1987) sites have contributed to our understanding of Late and Final Jomon lifeways. Recently, the excavations of Jomon wet sites, found for the first time in this region, have brought to light numerous well-preserved organic materials (Ginoza Village Board of Education 1999; Tomon 1998). Thus there is much more archaeological data today than in the 1950s when the Ocean Road hypothesis was proposed. How does the Ocean Road hypothesis hold up today?

Two important papers tested Yanagita's hypothesis against the archaeological data (Kokubu 1976; Shirakihara 1995). Kokubu (1976) mainly uses data obtained before the Reversion ${ }^{2}$ to Japan in 1972, and Shirakihara (1995) considers the latest information to test the hypothesis. Kokubu (1976) first examines whether the elements of the Lungshanoid culture, from which the hypothesized drifters originated, exist in the archaeological data from Okinawa. Although the concept of a Lungshanoid culture is no longer viable, at the time it was characterized by a fisher-farmer economy and black and gray ceramics. At the time, the Lungshanoid culture was thought to range from southeastern China to western Taiwan (Chang 1977:168-172 for the explanation of this culture). Several Lungshanoid sites in Taiwan had stone sickles, stone knives, stone spades, and rice-grainimpressed pottery sherds. None of these artifacts was known from the Ryukyu archipelago as of 1976. Secondly, Yanagita believed the Ryukyu archipelago, especially Miyako Island, was the island where the drifters would have landed because he speculated that the natural distribution of cowrie shellfish species were limited to this region. However, when Kokubu (1976) reviewed the natural distribution of this shell, he notes that cowrie was distributed more widely than Yanagita thought. Finally, Kokubu (1976:30), having examined the environment of the archipelago, reached the conclusion that Miyako Island would have been "especially hopeless for the introduction of wet rice agriculture because of low and inconsistent water availability of the island" (Kokubu 1976:30). Consequently, Kokubu (1976:30) concluded that Yanagita's hypothesis was "pure imagination."

Would new archaeological data collected after the Reversion support the Ocean Road hypothesis? Shirakihara (1995) has also reconsidered the Ocean Road hypothesis, this time using information collected in the last two decades. He demonstrates that, while prehistoric cultural contacts between Kyushu and Okinawa are often recognized in the archaeological record, it does not evidence a relationship between Mainland China or Taiwan and Okinawa.

Assuming that wet-rice agriculture was introduced to Okinawa between the Final Jomon and Yayoi periods, Shirakihara (1995) also examines settlement patterns and what he calls "special artifacts." Most sites during the period concerned are located on sand dunes. According to him, in front of the sites are either coral reefs or marshes, both of which are not suited for wet-rice agriculture. Also, behind the sites are cliffs and Quercus primary forest, again not ideal for wet-rice agriculture. Thus, the settlement location is not conducive to wet-rice agriculture (Shirakihara 1995:291). He further speculates that in such an environment, both wet-rice agriculture and dry-field rice production would have been impossible (Shirakihara 1995:291). The "special artifacts" include stone knives, stone axes, metal objects such as coins and copper arrowheads, and glass beads, all of which are related to mainland Yayoi, not to Mainland China or Taiwan. Also, some burial practices such as the use of stone coffins seem to have been intro- 


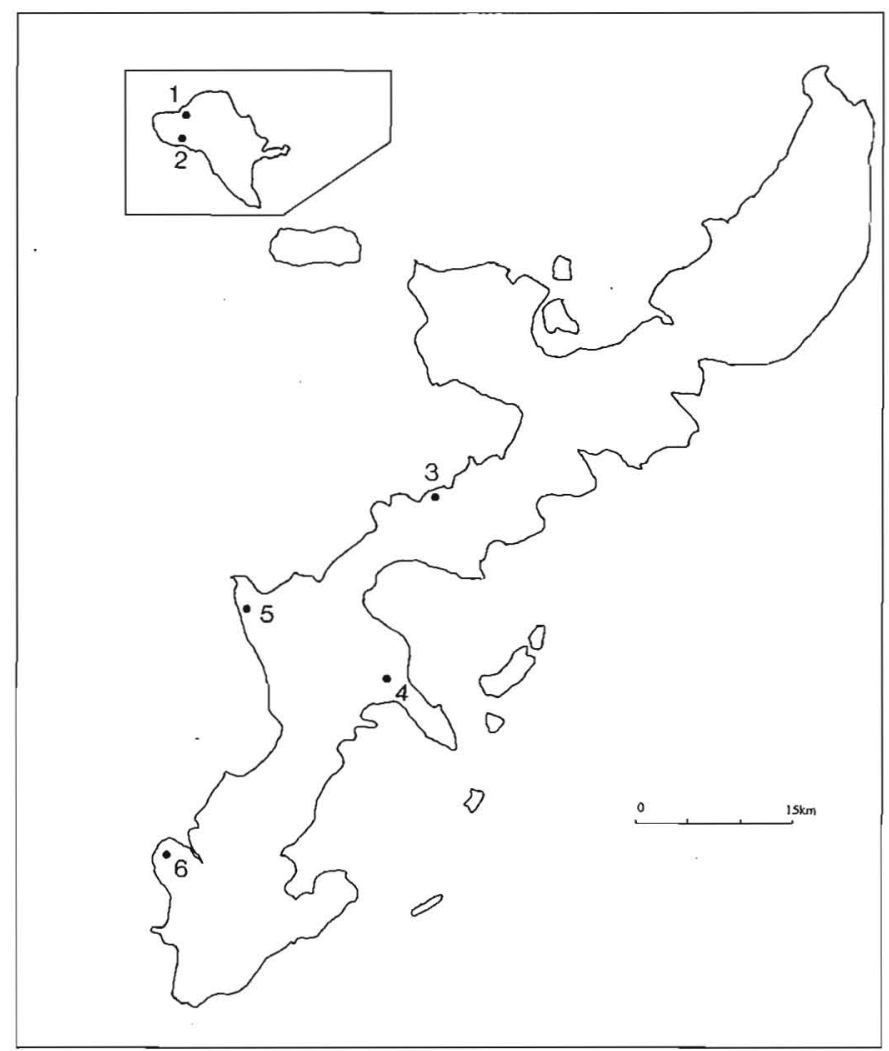

Fig. 3. Map of Okinawa. Location of important sites mentioned in the text. 1: Yajiyagama site. 2: Shimizu shell midden. 3: Atta shell midden. 4: Nigamashibaru site. 5: Takachikuchibaru site. 6: Nazakibaru shell midden.

duced to Okinawa from the north but not from the south. Thus, Shirakihara $(1995: 297)$ concludes that "at the present time, it is hardly possible to support the Ocean Road hypothesis." Shirakihara's comment is also applicable to the New Ocean Road hypothesis. That is, archaeological data do not support the New Ocean Road hypothesis either.

How early does the evidence for rice agriculture date in Okinawa? Prior to 1992, the earliest rice grains were from the Early Gusuku period Yajiyagama site (Fig. 3) on Kume Island (Asato 1991; Nitta 1982). Archaeologists in Okinawa attempted to recover plant remains, especially focusing upon rice and other crops from pre-Gusuku sites. For example, Kin (pers. comm. 1992, 1995) used water separation at the Atta shell midden in order to collect plant remains (Fig. 3). Although he washed large amounts of soil, no plant remains were recovered. Nitta (Gushikawa City Board of Education 1977) also carried out water separation at the Nigamashibaru site (Fig. 3) in order to examine the Final Jomon agriculture hypothesis. All he obtained were small quantities of wild plant remains, such as nut fragments. The Atta shell midden mentioned above and the Shimizu shell midden (Fig. 3) on Kume Island, dated to the Yayoi period, have yielded pottery 
sherds with rice-grain impressions (Kin pers. comm. 1992, 1995; Okinawa Prefecture Board of Education 1989). Both are interpreted as the result of exchange with the mainland Japanese (Morimoto and Higa 1994:66). Because of this evidence, it seemed that rice did not have a long history in the Okinawa archipelago.

While archaeological data do not support the Southern route hypothesis, several pieces of information from other disciplines suggest it is still a possibility. For example, the stepping-stone configuration of islands would have made easy access for the fisher-farmers of Taiwan or Fuchien to Japan (Chen Wenhua 1989, 1990). Based on the fact that rice-agriculture-related artifacts recovered from Taiwan date to 4000 B.P., Chen argues that "in ancient times when voyaging technology was not yet highly developed (the Southern route) is more realistic and probable than the Northern or Chanjian (central coastal China), routes" (Chen Wenhua $1989: 38)$. He attempts to explain the so-called broad-leaf evergreen forest zone cultural elements, such as high-rise storage houses and tooth extraction customs, as having all been introduced to Japan along this route. Furthermore, according to Chen, the Japanese language contains many South Chinese words, such as the Japanese word for rice, kome. Chen feels that this is evidence for rice having been introduced from Fuchien or Taiwan to Japan through the Ryukyu archipelago (Chen Wenhua 1989:38, 41-44, 1990) although Chen's view on linguistic interpretation seems to be a minor view (e.g., Hudson 1994).

While Chen's arguments do not lend strong support to the Southern route hypothesis, other circumstantial evidence comes from ethnology and botany. For example, traditional Okinawan wet-rice agriculture is characterized by preparing fields by ox or cow trampling. Oxen or cows are released in the paddy field and walk in the field to prepare the paddies. The distribution of this method of field preparation is mainly found from the Ryukyu archipelago to islands farther south such as Indonesia, to Sri Lanka, western India, and as far west as Madagascar (Takaya 1984); it is rarely seen in mainland Japan. Thus, it is a southern agricultural method (Takaya 1984:8). This method was recorded in Okinawa by the fifteenth century A.D. (Takaya $1984: 5$ ).

Another piece of circumstantial evidence supporting the Southern route hypothesis is the seasonality of cropping rice. The traditional Ryukyu wet-rice agriculture system is not the same as that of mainland Japan. In mainland Japan, rice is seeded in the spring and harvested in the fall. In the Ryukyu archipelago, rice was traditionally seeded in the fall to winter and harvested in the early summer (Kobayashi 1992; Takaya 1984; Watabe 1993b). Kobayashi (1992) compares Okinawan wet-rice agriculture seasonality practiced some 70 years ago with that practiced in Kagoshima, the nearest Japanese prefecture to Okinawa. Although Kagoshima is the neighboring prefecture, the agricultural system of Kagoshima was the same as on mainland Japan but different from the Okinawan system. This system is also known by the fifteenth century A.D. in Okinawa (Kobayashi 1992:15). As in the case of the animal trampling method, this winter cropping system has a mainly southern distribution (Takaya 1984:10).

In addition to animal trampling and winter cropping, one more element supports the Southern route hypothesis. In 1969, Morinaga and Mukai (1969) examined 22 traditional rice types (six from the Yaeyama archipelago, two from the Miyako archipelago, six from southern Okinawa, and six from the middle part of 
Okinawa). Consequently, they found that traditional Okinawan rice differs from standard japonica (O. sativa japonica) rice by having longer awns, longer ears, greater height, less branching, and by several other features not seen in $O$. s. japonica.

As a result of this research, Morinaga and Mukai (1969) conclude that the traditional rice in Okinawa was neither japonica nor indica rice but rather it was $O$. s. javanica. This conclusion is supported by others (for example, Sato 1992, 1993; Watabe 1993a, 1993b). The traditional Okinawan rice likely originated in southern regions. Accordingly, Watabe (1993a: 174) feels that it is conceivable that this variety of rice was introduced into Japan through the Ryukyu Islands prior to the Yayoi period. This is referred to as the New Ocean Road hypothesis in this paper.

Sato $(1992,1993)$ has rice genetic data that seem to support the Southern route. He pays special attention to the fact that rice was grown in paddy fields during the Middle Yayoi in the northernmost region of Honshu (Aomori Prefecture). He attempts to explain how and why it was possible to carry out wet-rice agriculture there at such an early stage of its introduction to Japan. According to Sato, in order for rice to grow in Aomori, it must be an early ripening variety of rice. However, Yayoi wet rice was a late ripening variety (i.e., japonica rice) (Sato 1992 :93). While it may be possible to explain the emergence of the early ripening variety as a consequence of mutation from the late ripening variety, Sato (1993: 93) argues that "it is difficult to imagine the former variety so easily evolving from the latter."

Instead of the mutation hypothesis, he has proposed a genetic exchange hypothesis. In Japan today, two varieties of rice grow. One is the most widely spread and cultivated variety in Japan, which Sato calls temperate japonica (O. sativa japonica). The other is the extremely minor and rarely recognized variety in this region, which Sato calls tropical japonica (O. sativa javanica). While these two varieties are both late ripening varieties, his experiment has demonstrated that when these two varieties were crossed, an early ripening variety was produced (Sato 1992:94-120). Based on these results, Sato has hypothesized that temperate japonica was introduced at the beginning of the Yayoi period, or shortly before into the Kyushu area. This rice crossed with the tropical japonica that had been introduced into this region through the Ryukyu archipelago much earlier than the Yayoi period. Consequently, the early ripening variety evolved, and because of this, it became possible to cultivate rice in paddy fields as far north as Aomori as early as the Middle Yayoi period. This helps explain the early success of rice in Aomori. In this case, as in the case of Watabe's hypothesis, the Southern route existed earlier than the date proposed by Yanagita. Sato's (1992) hypothesis implies that rice entered Japan from a southern source before the onset of the Yayoi period. This suggests the possibility of the New Ocean Road hypothesis.

I have reviewed the Southern route hypothesis based on data from archaeological and related fields. While archaeological data do not support this hypothesis, geographical, ethnographical, and botanical data imply the possibility of the introduction of rice into mainland Japan through the Ryukyu archipelago. This may have happened during the Jomon period, as the New Ocean Road hypothesis suggests, or at the beginning of the Yayoi period, as Yanagita has suggested with his famous Ocean Road hypothesis. These lines of evidence discussed above are, however, circumstantial. Archaeological data, such as settlement location or certain artifacts, may suggest the absence of food production as we have seen in 
Shirakihara's (1995) conclusion or, on the other hand, may imply the presence of food production. These data are insufficient to demonstrate the presence of agriculture, however. No matter how strongly the data from the related fields suggest agriculture in the past, they cannot provide precise timing. That is, the several lines of evidence mentioned above could be of recent origin, and not as ancient as these scholars would like to think.

Therefore, in order to test the Southern route or Ocean Road hypothesis, the direct evidence of plant remains is required. Since 1992, I have applied flotation at several sites in Okinawa in order to obtain plant remains. Prior to the first application of flotation in Okinawa, it was commonly believed among Okinawan archaeologists that it was impossible, or nearly impossible, to recover plant remains from archaeological sites on the islands. However, flotation has provided good evidence. The following section will describe macroplant remains obtained from two sites, the Nazakibaru site and Takachikuchibaru shell midden (Fig. 3).

Before introducing the results, it is necessary to briefly summarize the period to which both sites belong. Both sites belong to the Yayoi-Heian period, which lasted approximately 1200 years. While the detailed chronology of this period has not been established because of a lack of a good composite site, archaeologists tend to subdivide it into early and late. While nearly 300 sites have been reported to date to the Yayoi-Heian period (e.g., Takamiya 1996a), most of them seem to belong to the early part of this period. Indeed, it is interesting to note that archaeologists can easily enumerate several early Yayoi-Heian sites but often have a hard time listing sites that belong to the later half when asked the same question.

The Early Yayoi-Heian period is characterized by several features. First of all, almost all sites are located on sand dunes, the elevation of which is less than $10 \mathrm{~m}$ and only several meters from the present-day shoreline. Second, they used pointed-based pottery. Third, the subsistence economy of this period includes shellfish and fish species available from the coral reefs. At the same time, consumption of wild boar seems to have increased during this period. This pattern of animal use is similar among the Early Yayoi-Heian period sites. No plant remains have been obtained from the Early Yayoi-Heian period sites before this study. During the Late Yayoi-Heian period, on the other hand, site location seems to have moved inland to higher elevations than the Early Hayoi-Heian sites (Takemoto 1972). They used flat-based pottery whose body is constricted towards the base. For this period, no faunal and plant remains have been recovered. Some speculate that food production may have begun during this period since food production could not have emerged suddenly during the following Gusuku period (Takamiya 1995). As we will see, the differences between these two subperiods not only include settlement location and pottery type, but also plant food they consumed.

\section{THE OCEAN ROAD HYPOTHESIS: ON THE BASIS OF THE DIRECT DATA}

\section{The Nazakibaru Site}

The Nazakibaru site is located in the capital city of Okinawa Prefecture, Naha (Fig. 3). The site dates between the eighth and tenth centuries A.D., during the Late Yayoi-Heian period. It is situated on a hilltop, approximately $20 \mathrm{~m}$ in eleva- 
tion and approximately $500 \mathrm{~m}$ inland. The Nazakibaru site is a typical Late Yayoi-Heian site in terms of its settlement location (Naha City Board of Education 1996:78). Approximately $1313 \mathrm{~m}^{2}$ were excavated, resulting in the recovery of about 2200 pieces of pottery and 9 lithic fragments. Most of the pottery belonged to the Late Yayoi-Heian period. The site is significant for two reasons. First is the recovery of a single Late Yayoi-Heian period level for the first time in Okinawa. Thus, the site is important to understand the transition between the Late Yayoi-Heian and the Gusuku periods (Naha City Board of Education 1996:78). The other is that the site has yielded agricultural features for the furst time from the pre-Gusuku period. The site has yielded more than 250 hoe marks and two lines of ditches. Although "indirect" data, they appear to be the earliest evidence of agriculture in Okinawa (Naha City Board of Education 1996).

Although the site has yielded the earliest agricultural related features in Okinawa, there were no house structures or hearths that were related to food processing or consumption. The only features that I thought would yield carbonized plant remains were five burned soil areas whose function is not clearly understood. Soil samples were collected from these five areas and the immediate surrounding areas. A total of 1687 liters of soil were processed by flotation, resulting in $118.93 \mathrm{~g}$ of light fraction. While the recovery rate was only about $0.07 \mathrm{~g}$ per liter of soil, the carbonized plant remains are significant to understanding the subsistence economy at this site. Table 2 shows identified plant remains from the flotation samples (Takamiya 1996b, 1997). Mugi-rui are either barley (Omugi in Japanese) or wheat (Komugi in Japanese), but their identification to either one of them is difficult because of poor preservation.

Table 2. The Nazakibaru Site Plant Remains

\begin{tabular}{llll}
\hline & & & $\begin{array}{c}\text { QUANTITY } \\
\text { SCIENTIFIC NAME }\end{array}$ \\
\hline Cultigens & & JAPANESE NAME & (PIECES OR FRAGMENTS) \\
Triticum aestivum & Wheat & Komugi & 2 \\
Hordeum vulgar & Barley & Omugi & 3 \\
Oryza sativa var. japonica & Rice & Ine & 2 \\
Setaria italica & Foxtail millet & Awa & 2 \\
Fabaceae & Bean family & Mame-ka & 20 \\
Wild species & & & 10 \\
Poaceae & Grass family & Ine-ka & 38 \\
Cyperaceae & Sedge family & Kayatsurigusa-ka & 8 \\
Polygonaceae & Knotweed & Tade-ka & 9 \\
Oxalis L. & Sorrel & Katabami-zoku & 22 \\
Phyllanthus urineria & Spurge & Komikansou & 73 \\
Euphorbia ? & & Toudaigusa-zoku & 46 \\
Solanaceae & Nightshade family & Nasu-ka & 29 \\
Asteraceae & Aster family & Kiku-ka & 150 \\
Unknown/Unidentifiableb & & & \\
\hline
\end{tabular}

a Wild or domesticated status is undetermined.

'Unknowns are plant remains which "are identifiable but not yet classified" (Crawford 1983:48) and Unidentifiable are plant remains that cannot be identified due to poor preservation of recovered seeds (Crawford 1983). 
Prior to the research at the Nazakibaru site, the earliest evidence of food production and actual cultigen remains was from the Yajiyagama site, dating to the early Gusuku period. The result of the present analysis has demonstrated that the people at the Nazakibaru site knew about cultigens. Furthermore, although approximately 1700 liters of soil have been processed by flotation, no nut meat nor shell (even a fragment) has been identified. The result implies that it is likely that the people at the site relied on agricultural products rather than wild species. More importantly, it is highly likely that these cultigens were actually produced locally rather than acquired through exchange with agriculturalists.

In addition to the agricultural related features, such as hoe marks and ditches mentioned above, associated plant remains strongly suggest agriculture was practiced at or near the site. Many of the identified wild species grow in disturbed areas. The seeds identified as Oxalis L. (likely Oxalis oxalis) and the Cyperaceae specimens (likely Scirpus juncoides) are the best examples. The former and Phyllanthus urineria are weed species of dry fields (Kasahara 1979). The latter is a weed species of wet paddy fields (Kasahara 1979; also Yoshizaki 1992b). Shima (pers. comm. 1992), a chief researcher for the excavation, mentions that the eastern part of the site was wet and used as a paddy field before World War II. Therefore, it is possible that people at the site were living in an environment where wet paddy field agriculture was possible. The Nazakibaru site, during the period of use, was not in a primary forest but in a disturbed open site. Since the site location is typical for this period, it seems safe to conclude that the people in Okinawa knew food production by this time.

Korean drifters landed in Yonaguni, the southwesternmost island in the Ryukyu archipelago, in the fifteenth century A.D. They stayed about one year and then moved northward through the chain of islands to mainland Okinawa, from where they safely returned to their home country. Once back home, they reported cultigens they saw on the islands they visited. According to them, barley, wheat, rice, foxtail millet, broomcorn millet, and legumes were grown at that time (e.g., Sasaki 1984). Archaeobotanical data obtained from the Nazakibaru site have demonstrated all but broomcorn millet and cultivated legumes were grown between five and seven hundred years before the Korean drifters' observation. It is likely that broomcorn millet and cultivated legumes were known to the Okinawans at about the same time. This will be tested in future research.

Archaeobotanical data from the Nazakibaru site have shown that food production, including rice agriculture, began at least by the eighth to the tenth centuries A.D. How much earlier can this agricultural record be traced? Can it be traced back as early as the Yayoi period as Yanagita proposed?

\section{The Takachikuchibaru Shell Midden}

The Takachikuchibaru shell midden is located in Yomitan village (Fig. 3) and dates to the Early Yayoi-Heian period. The site location, approximately 10 to $15 \mathrm{~m}$ from the present shoreline with an elevation of 5 to $10 \mathrm{~m}$ on a sand dune, is typical of Early Yayoi-Heian site locations in Okinawa. While the analyses of ceramics and lithics have not been completed yet, the artifacts recovered from the site show characteristics of this period (Nakasone, pers. comm. 1996). Several sites in Okinawa dating to this period have yielded pottery manufactured in mainland 
Table 3. The Takachikuchibaru Shell Midden Plant Remains

\begin{tabular}{|c|c|c|c|}
\hline SCIENTIFIC NAME & ENGLISH NAME & JAPANESE NAME & $\begin{array}{c}\text { QUALITY } \\
\text { (FRAGMENTS)/ } \\
\text { WEIGHTS (g) }\end{array}$ \\
\hline Castanopsis sieboldii Hatushima & Indian chestnut & Itajii & \\
\hline C. sieboldii nut meat & & & $32 / 0.31$ \\
\hline Fagaceae & Beech & Buna-ka & \\
\hline Fagaceae nut meat & & & $100 / 1.29$ \\
\hline Fagaceae nut shells & & & $1657 / 6.07$ \\
\hline Persea thumbergii Kostermans & Type of red bay & Tabunoki & \\
\hline P. thumbergii meat & & & $33 / 0.44$ \\
\hline Fagaceae or $P$. thumbergii meat & & & $135 / 0.58$ \\
\hline Vitaceae & Grape family & Budo-ka & 1/NIL \\
\hline Actinidia rufa Planch. & Silvervine & Nashikazura & $11 / \mathrm{NIL}$ \\
\hline Solanaceae & Nightshade family & Nasu-ka & 1/NIL \\
\hline Unknown/unidentifiable & & & $370 / 1.78$ \\
\hline
\end{tabular}

Note: NIL = less than $1 \mathrm{mg}$.

Japan. While no imported pottery was recovered at the Takachikuchibaru shell midden, the site has yielded one artificially modified Tricornis latissimus shell. Such shell was often sent to mainland Japan where Yayoi chiefs used it as a symbol of authority (Nakasone 1995). Furthermore, faunal remains obtained from the site also show similarities with faunal remains from other Early Yayoi-Heian sites. In short, Takachikuchibaru is a typical Early Yayoi-Heian site.

Approximately $320 \mathrm{~m}^{2}$ were excavated. Here again, unequivocal features relating to food preparation or consumption were not discovered. Instead, there were two grids $(2$ by $2 \mathrm{~m}$ ) in which mollusk remains were concentrated. These concentrations of mollusk remains are likely products of subsistence activity. Accordingly, it was speculated that these two grids would have been the only grids where plant remains could be recovered from the site. A total of 2050 liters of soil from these two grids and an additional 412.5 liters from eight other grids were collected for flotation. This resulted in recovery of $2743.66 \mathrm{~g}$ of light fraction. Archaeobotanical remains obtained from this site are completely different from the Nazakibaru site remains (Table 3 ).

Because the plant remains, except for Castanopsis sieboldii Hatushima, are smaller than $2 \mathrm{~mm}$, and are poorly preserved, it was difficult to identify Fagaceae nut meats to genus or species level. Thus, all nut meats, except positively identified C. sieboldii, are categorized as Fagaceae. This category therefore includes four Quercus species, one Lithocarpus species, and questionable C. sieboldii remains. In addition, because fragments of Fagaceae nut meats and Persea thumbergii seeds between $2 \mathrm{~mm}$ and $4 \mathrm{~mm}$ in size were difficult to distinguish, they are grouped together.

All plant remains recovered from the site are wild species (Table 3). Nuts, which are thought to have been important plant food for the prehistoric Okinawans, dominate the assemblages. Among the nut remains, nut shells predominate both in terms of number and weight. The fact that nut shells are recovered more often than nut meats may be accounted for by the fact that the site is a shell mid- 
den, that is, a place where unused material was discarded. Whereas $P$. thumbergii remains are known from three other prehistoric sites in Okinawa, the importance of this plant species as food is not yet clearly understood (Watanabe 1989). In addition, since both Vitaceae and Actinidia seeds can be consumed while eating, these may be underrepresented.

In terms of the topic of this paper, the most important finding from the Takachikuchibaru shell midden is that, unlike the Nazakibaru population, people at this site appear to have gathered and relied upon wild plants. Since the site is otherwise typical of the Early Yayoi-Heian period in Okinawa, it can be safely concluded that people in Okinawa at this time appear not to have practiced any agriculture.

\section{DISCUSSION AND CONCLUSION}

Archaeobotanical studies conducted at the Takachikuchibaru shell midden and Nazakibaru site have revealed that no form of food production was practiced in Okinawa during the Early Yayoi-Heian period, but that it was present in this region later, at least by between the eighth and tenth centuries A.D. The result implies that food production on the island began somewhere between the second and eighth to tenth centuries A.D. Based on the fact that settlement pattern changes about the sixth century A.D., I have stated that agriculture in Okinawa started at about this time (Takamiya 1996c, 1997). However, macroplant remains collected from column sampling at the Yomisaki site, dated from the sixth to the eighth centuries A.D. on Amami Island, implies that wild plants were mainly consumed at that time (Takamiya 1998a). Because the sampling method was column sampling and only 30 liters of soils were processed by flotation, only two Fagaceae meat fragments, one Persea thumbergii fragment, and one unknown seed fragment were recovered. If the Yomisaki plant remains represent the reality of that time period, then it would indicate that food production began in this region rather abruptly between the eighth and tenth centuries A.D. In any case, this study does not support the Ocean Road hypothesis proposed by Yanagita. Furthermore, the Nazakibaru agricultural system likely originated in mainland Japan (from the north), not from the south (Takamiya 1996c, 1997, 1998b). During the Early YayoiHeian period, Okinawa was heavily involved in exchange with mainland Yayoi people. While most regions of Japan accepted wet-rice agriculture immediately after such contact, prehistoric Okinawan populations did not "jump" to this new subsistence system.

Yanagita's hypothesis is thus invalidated for the first time on the basis of direct evidence obtained by using flotation. In short, archaeobotanical data, like the rest of the archaeological record, do not support the Ocean Road hypothesis. The New Ocean Road hypothesis is suggestive. However, the difficulty of testing it is that it is often impossible to assign dates to proposed events. An "older or more primitive type" based on, for example, morphological similarities, may not always be the old type. If the animal trampling method originated in the south, then one would expect the ox or cow associated with wet-rice agriculture in the past to be biologically similar to those in southern regions. However, according to Nishinakagawa (1991), a faunal analyst, the oldest ox and cow specimens recovered from Okinawa, dating to the Gusuku period, are all within the range of variation of the 
mainland Japanese ox and cow. The "older or primitive" type may not necessarily be the old one. The same can be also said for the timing of the introduction of O. s. javanica to Japan since genetics cannot provide a chronology (Sato 1992:133).

Instead of evaluating the New Ocean Road hypothesis, I would like to conclude this paper with one suggestion. Chen Wenhua (1989:33) writes that it is possible that there were several routes from which rice was introduced into Japan. One possible route is the Southern route discussed above. However, this hypothesis only attempts to explain a pathway through which rice (and recently other cultural elements) was introduced into mainland Japan. Consequently, a broad arrow is usually drawn from southern China and Taiwan to Japan through the Ryukyu archipelago (Fig. 1). Whenever the Southern route hypothesis is discussed, no one considers how people along the line reacted to the introduction. For example, did they need rice during the Yayoi or Jomon period? For the prehistoric Okinawans, how significant was the Southern route? If the New Ocean Road hypothesis was correct, why would the Jomon Okinawans have accepted rice? Based on data from the other island cases, I would expect that people in Okinawa during the late Middle to Late Jomon may have needed agriculture in order to colonize the island (Takamiya 1993, 1996c, 1997). However, I feel that this agriculture may have originated from the north, not from the south, since no archaeological data indicate that the late Middle to Late Jomon culture elements have any link to the south (e.g., Takamiya 1994b). Furthermore, if the New Ocean Road hypothesis is acceptable, then it would suggest that the prehistoric Okinawans shifted subsistence strategies from "rice" farmers to plant gatherers during the Early Yayoi-Heian, as has been seen from the Takachikuchibaru shell midden data. That is, they switched from farming to foraging. The New Ocean Road hypothesis is not well equipped to explain this shift.

The Southern route hypothesis may be significant for the explanation of the formation of mainland Japanese cultural elements. However, it treats the prehistoric population of Okinawa as passive actors and does not account for the dynamic relationship between people and their subsistence (agriculture). From the perspective of the prehistoric Okinawans, not the mainland Japanese, it is difficult to perceive why they needed rice agriculture from the south. For many scholars who are interested in the origins of rice agriculture in Japan, it seems to have been important whether or not rice was introduced via the Southern route (or other routes). This may be dominant in the future. However, it is important to consider the cultural background (including ecological factors) of the people who lived there when one examines this hypothesis rather than merely view the archipelago as a "route" of rice introduction.

It is this kind of approach that makes the Southern route hypothesis anthropologically most interesting. For example, by the Late Jomon period, huntergatherers had successfully colonized the Okinawa archipelago, and continued this subsistence economy until the sixth to eighth centuries A.D. (Takamiya 1996a, $19966)$. This implies that the indigenous foragers must have had an opportunity to encounter the rice farmers from the south if the hypothesis rejected in this paper is plausible, since even the largest island in the archipelago, Okinawa, is only 100 $\mathrm{km}$ in length and 10 to $20 \mathrm{~km}$ in width. How did foragers react to this encounter? Did they accept or refuse the new subsistence economy, and why? An attempt to answer these questions will definitely contribute to our understanding of the 
spread of food production in other parts of the world, such as Europe (e.g., Price 2000).

\section{ACKNOWLEDGMENTS}

Motomu Nakasone of the Yomitan Village Board of Education, Seiki Kin and Hirosh Shima of the Naha City Board of Education, Masayuki Komoto, and Naoko Kinoshita provided me the opportunity to collect soil samples from, respectively, the Takachikuchibaru shell midden, Nazakibaru site, and Yomisaki site for this research. Gary Crawford has given me valuable comments. I would also thank three reviewers and editors for Asian Perspectives, especially M. Stark for reading and commenting on earlier drafts of this paper. The Sasakawa Graduate Student Fellowship at UCLA and the Wenner-Gren Foundation for Anthropological Research Small Grant (Gr. 5501) provided financial support to conduct this study.

\section{NOTES}

1. In this paper, the Southern route hypothesis refers to both the Ocean Road and New Ocean Road hypotheses. When the paper considers the introduction of rice through this route between the Final Jomon and Yayoi period, it is referred to as the "Ocean Road hypothesis." When it refers to the introduction of rice through this route during the Jomon period, it uses the term the "New Ocean Road hypothesis."

2. The Prefecture of Okinawa was returned to Japan in 1972 from the United States who occupied the islands since World War II. This event is known as "Hondo fukki," which has been translated as "Reversion to Japan."

\section{REFERENCES CITED}

AKAZAWA, TAKERU

1982 Culture change in prehistoric Japan: Receptivity to rice agriculture in the Japanese archipelago, in Advances in World Archaeology, vol. 1: 151-211, ed. by F. Wendorf and A. E. Close. New York: Academic Press.

Asato, Susumu

1991 Koukogaku kara mita Ryukyu-shi (History of the Ryukyus: Archaeological Perspectives). Naha City: Hirugi-sha.

BABA, HISAO

1993 Minatogawa-jin wa Yosomono nanoka? (The Minatogawa People-were they foreigners?) Gen Nihon-jin Yayoi-jin to Jomon-jin no Nazo Asahi One Theme Magazine 14:5972.

Crawford, G.

1983 Paleoethnobotany of the Kameda Peninsula Jomon. Ann Arbor, Michigan.

Chang, KWANG-CHIH

1977 The Archaeology of Ancient China. New Haven: Yale University Press.

Chen Wenhua

1989 Chugoku no Inasaku Kigen wo meguru shomondai (Several problems on rice agriculture origins in China), in Chugoku no Inasaku Kigen: 9-46, ed. Chen Wenhua and Tadayo Watabe. Tokyo: Rokko Shuppan.

1990 Wa no Furusato-Ine to kita shuzoku (The home of Japanese-manners and customs introduced with rice), in Ine-Sono Genryu eno Michi: 50-51, ed. Higashi Ajia Bunka Kouryushi Kenkyu Kai. Saga: Higashi Ajia Kouryushi Kenkyu Kai.

D'ANDREA, A. C.

1995 Later Jomon subsistence in northeastern Japan: New evidence from paleoethnobotanical studies. Asian Perspectives 34 : 195-227.

D'Andrea, A. C., G. W. Crawford, M. Yoshizaki, and T. Kudo

1995 Late Jomon cultigens in northeastern Japan. Antiquity 69:146-152. 
Dor, N.

1997 Okinawa no Kaseki Jinrui (Human fossil remains from Okinawa), in Nanto no Hito to Bunka no Kigen: 19-29, ed. Kokogaku Kyokai Gakushuu Kai Jikkou Iinkai. Naha City: Kokogaku Kyokai Gakushuu Kai Jikkou Iinkai.

Fujiwara, Hiroshi

1998 Inasaku no Kigen wo Saguru (To search for the origins of rice agriculture). Tokyo: Iwanami shoten.

Ginoza Village Board of Education

1999 Mebaru Iseki (The Mebaru site). Ginoza Village: Ginoza Village Board of Education.

Gushikawa City BoARd OF EduCATION

1977 Nigamashibaru Iseki (The Nigamashibaru site). Gushikawa City: Gushikawa City Board of Education.

HiguChI, TAKAYUKI

1990 Ine no Denrai to Nihon no Yoake (The introduction of rice and the dawn of Japan), in Ine-sono Genryu heno Michi: 18-19, ed. Higashi Ajia Bunka Koryu-shi Kenkyu kai. Saga: Higashi Ajia Bunka Koryu-shi Kenkyu kai.

Hudson, M.

1994 The linguistic prehistory of Japan: Some archaeological speculations. Anthropological Science $102(3): 231-225$.

n.d. The agriculture threshold in the Japanese Islands, in From the Jomon to Star Carr, ed. L. Janik, S. Kaner, A. Matsui, and P. Rowley-Conwy. Oxford: Oxbow Books. (In press)

Kasahara, YASUO

1979 Zassou no Rekishi (History of Weeds), in Zassou no Kagaku: 69-135, ed. M. Numata. Tokyo: Kensei-sha.

KOBAYASHi, SHIGERU

1992 Nanseishotou ni okeru Ine-saibai no Seiritsu Joken (The conditions for the beginning of rice cultivation in the Southwestern Archipelago). Kokogaku Janaru 352:15-20.

KoKuBU, NAOICHI

1976 Kan-shina kai Minzoku Bunka-ko (A Consideration of Ethnography of the Circum-China Sea). Tokyo: Keiyuu-sha.

Morimoto, Isao, and Higa Yuko

1994 Okinawa Shutsudo no Kaibocho-you Seihin ni tsuite (On the Shell Knife-like Artifact). Nanto Koko 14:65-82.

Morinaga, Toshitaro, and Yasushi Mukai

1969 Okinawa Shotou no Zairaiine ("Traditional" rice in the Okinawa Archipelago). Nogyo oyobi Engei 44(1): 11-16.

NaKasone, Motomu

1995 Kohoura sei Kaiwa no Seisaku Koutei ni Kansuru Shiryo (Data on the process of manufacturing Tricornis latissimus shell bracelet). Nanto Koko Dayori 53:2.

Naha City Board of Education

1996 Nazakibaru Iseki (The Nazakibaru site). Naha City: Naha City Board of Education.

Nishinakagawa, HaYaO

1991 Kodai Iseki Shutsudokotsu karamita Waga Kuni no Ushi, Uma no Toraiki to sono Keiro ni Kansuru Kenkyu (The Study of the Japan Ox/Cow and Horse Bones Recovered from Archaeological Sites to Understand Timing and Routes of Their Introduction). Kagoshima City: Kagoshima Daigaku Nogakubu Juigakka.

NitTA, JUSEI

1982 Umi ya Yama ni Shokumotsu wo motomete-Kaizuka kara Hakkutsu sareru Shokuryo Zanshi (Searching for food to the sea and mountain-ecofacts recovered from archaeological sites). Shin Okinawa Bungaku $355: 32-36$.

OKInawa City Board of Education

1979 Murokawa Kaizuka (The Murokawa shell midden). Okinawa City: Okinawa City Board of Education.

\section{Okinawa Prefecture Board of Educatron}

1985 Shinugudo Iseki (The Sinugudo site). Naha City: Okinawa Prefecture Board of Education. 1987 Kogachibaru Kaizuka (The Kogachibaru shell midden). Naha City: Okinawa Prefecture Board of Education. 
1989 Shimizu Kaizuka (The Shimizu shell midden). Naha City: Okinawa Prefecture Board of Education.

PRICE, D. (ED.)

2000 Europe's First Farmers. Cambridge: Cambridge University Press.

Sahara, Makoto

1978 Kome wo Tabete Nisen-nen (2000 years since eating rice). Rekishi Koron 4(3): 128.

1987 Taikei Nihon no Rekishi 1 Nihon jin no Tanjo (An outline of Japanese history 1, the birth of Japanese). Tokyo: Shogakkan.

SASAKI, КOMEI

1971 Inasaku Izen (Before Rice Agriculture). Tokyo: NHK Books.

1984 Nantou no Dentouteki Inasaku Noko Gijutsu (The traditional rice agriculture technology in the Southern Islands), in Nanto no Inasaku Bunka: 29-66, ed. T. Watabe and S. Ikuta. Tokyo: Hosei University Press.

1991 Nihon no Rekishi 1 Nihon-shi Tanjo (History of Japan 1, the beginning of Japanese history). Tokyo: Shueisha.

SATO, YOICHIRO

1992 Ine no Kita Michi (The route through which rice was introduced). Tokyo: Shokado.

1993 Idengaku kara mita Ine no Denrai to Inasaku-bunka no Juyo (Diffusion of rice and acceptance of rice agriculture: Genetic perspectives), in Nihon Bunka no Kigen (The Origins of Japanese Culture): 159-192, ed. K. Sasaki and K. Morishima. Tokyo: Kodansha.

Shirakihara, KazUmi

1995 Nansei Shoto no Ine no Michi (The rice road in the Southwestern Archipelago), in Higashi Ajia no Inasaku Kigen to Kodai Inasaku Bunka Hokoku Ronshu: 289-300, ed. K. Wasano. Saga City: Saga Daigaku Nogakubu.

TAKAHASHI, MAMORU

1997 Jomon Jidai Chuki Inasaku no Tankyu (The investigation of the Middle Jomon period rice cultivation), in Kashida Choku Sensei Koki Kinen Ronbun Shu: 1-21, ed. Kashida Choku Sensei Koki Kinen Ronbun Shu Kanko-Kai. Kyoto: Shiyo-sha.

TAKAMIYA, HiRoe

1994 aruma no Shimajima (The islands in the Uruma region), in Okinawa no Senshi Iseki to Bunka: 3-25, ed. by Hiroe Takamiya. Tokyo: Daiichi shobo.

19946 Nanto (The Southern Islands), in Okinawa no Senshi Iseki to Bunka: 40-46, ed. by Hiroe Takamiya. Tokyo: Daiichi shobo.

1995 Kaigentsuho kara mita Senshi Shumatsu ki no Okinawa (On the Late Prehistoric period of Okinawa based on the study of ancient Chinese coins), in Ocho no Kokogaku: 267-286, ed. by Okawa Kiyosh Hakushi Koki Kinen Ronbunshu Iinkai. Tokyo: Yuzankaku.

TAKAMIYa, Hiroto

1993 Senshi Jidai no Okinawa Honto ni okeru Hito no Tekio Katei (The adaptation processes of human population on mainland Okinawa in prehistoric times). Kobunnka Danso $30: 1089-1107$.

1996a Initial colonization, and subsistence adaptation processes in the Late Prehistory of the Island of Okinawa. Indo-Pacific Prehistory Bulletin 15:143-150.

1996 Kodai Minzoku Shokubutsu Gaku teki Apurochi ni yoru Nazakibaru Iseki no Seigyo (The subsistence economy of the Nazakibaru site: Paleoethnobotanical approach), in Nazakibaru Site: $83-100$, ed. Naha City Board of Education. Naha City: Naha City Board of Education.

1996c Okinawa Shoto ni okeru Noko no Kigen-Okinawa Honto wo Chushin ni (The origins of agriculture in the Okinawa Archipelago: Focusing on the mainland Okinawa). Kokusai Nihon Bunka Senta Sosho 12:117-132.

1997 Subsistence Adaptation Processes in the Prehistory of Okinawa. Ph.D. diss., Department of Anthropology, University of California, Los Angeles.

1998a Yomisaki Iseki (Amami Oshima Kasari Cho) ni Okeru Furoteshon-ho no Donyu to Sono Seika ni Tsuite (An application of the flotation method at the Yomisaki Iseki [Kasari Town, Amami Island]), in Kokogaku Kenkyu Hokokusho 33:46-48, ed. Kumamoto University Archaeology Research Team. Kumamoto: Kumamoto University Archaeology Team.

1998b Gendai Okinaua Jin no Kigen. (The origins of the modern Okinawans). Hikaku Bunka Ranso $1: 55-79$.

TAKAYA, KOICHI

1984 Nanto no Nogyo Kiban (Agricultural basis in the Southern Islands), in Nanto no Inasaku Bunka: 2-28, ed. T. Watabe and S. Ikuta. Tokyo: Hosei Daigaku Shuppan. 
Takemoto, Masahide

1972 Okinawa ni okeru Genshi-shakai no Shumatsu-ki (The terminal period of Okinawa primitive society), in Nantoshiron: 347-365, ed. by Ryukyudaigaku Shingakkai. Naha: Ryukyudaigaku Shingakkai.

TOMON, KENJI

1998 Kyanpu Kuwae nai Shikutsu Chosa no No. 143 ni tsuite (On the test excavation at No. 143 in the Camp Kuwae). Nanto Koko Dayori 59:1.

WaTABE, TADAYO

1993a Umiwo Watatta Ine (Rice which crossed the ocean), in Ine no Daichi: 147-180, ed. T. Watabe. Tokyo: Shogakkan.

$1993 \mathrm{~b}$ Inasaku no Nansei shoto heno Hokujo (The northward introduction of rice agriculture to the Southwest Archipelago), in Ine no Daichi: 210-222, ed. T. Watabe. Tokyo: Shogakkan.

1993c Ine no Daichi (The earth filled with rice). Tokyo: Shogakkan.

WatANABE, MaKoto

1989 Miyagi jima Takamine Iseki Shutsudo no Shokubutsu Itai (Plant remains recovered from the Takamine site, the Miyagi Island), in Miyagijima Iseki Bunpu Chosa Hokoku: 217-218, ed. Okinawa Prefecture Board of Education. Naha City: Okinawa Prefecture Board of Education.

Yanagita, Kunio

1993 [1952] Kaojo no michi (The Ocean Road). 19th ed. Tokyo: Iwanami shoten.

Yoshizaki, MasaKazU

1992 a Kodai Zakkoku no Kenshutsu (Recovery of ancient millets). Kokogaku Janaru 356:2-14.

$1992 b$ Aomori ken Yahata Iseki 12go Jukyo kara Kenshutsu sareta Zakkokurui to Kome hoka no Shokubutsu Shushi (Millets, rice, and other plant remains recovered from the 12 th house at the Yahata site, Aomori Prefecture). Yahata Iseki Hakkutsu Chosa Hokoku sho II: 59-73, ed. by Yachinohe City Board of Education. Hachinohe City: Hachinohe City Board of Education.

1997 Higashi wa Hie, Nish wa Ine. Jomon Jidai no Saibai Shokubutsu (Cultigens during the Jomon period: barnyard millet in the East and rice in the West). Rekishikaido 10:123125.

1998 Kokumotsu: Kotonaru Kokumotsu wo Tazusaeta samazama na. Hitobito ga Nippon Retto ni Yattekita (Crops: Variety of crops were introduced into the Japanese Archipelago by different Populations). Gyakuten no Nihonshi Nihonjin no Rutsu Kokomade Wakatta!: 69-77, ed. by Yousen sha Mook. Tokyo: Yosensha.

Yomitan Village Board of Education

1977 Toguchiagaribaru (The Toguchiagaribaru site). Yomitan Village: Yomitan Village Board of Education.

\section{ABSTRACT}

The beginning of rice agriculture in Japan impacted every aspect of life in most parts of the archipelago. It was the Japanese version of the "Neolithic Revolution." Because rice is so important today for Japanese and thought to have been so since the Yayoi period, when and how rice agriculture began in Japan has been intensively studied. Accordingly, three hypotheses, (1) Northern, (2) Chanjian (central coastal China), and (3) Southern routes have been proposed. The third hypothesis was originally proposed by the well-known ethnologist Kunio Yanagita in 1952. Since then, many scholars have attempted to examine this hypothesis. The possibility of this hypothesis based on archaeological, botanical, and ethnological data that have been accumulated in the last fifty years is summarized. Direct data, plant remains that I was able to collect and analyze to test this hypothesis are evaluated. The archaeobotanical data suggest that food production began on the island of Okinawa from the eighth to tenth centuries A.D. and foragers were living on the island during the Yayoi period. The data thus agree with archaeological data and the Southern route hypothesis is rejected. KEYwORDS: origins of rice agriculture in Japan, the Southern route, archaeobotanical data, Ryukyu archipelago, Okinawa. 